\title{
ONCOLL: A quasi-experimental study on the effect of a web- based platform on teaching collocations
}

\author{
Ahmet Basal a *(D), Muhammet Toraman a (D), Kiymet Merve Celen ${ }^{b}$ (D) \\ a Yildiz Technical University, İstanbul 34220, Turkey \\ ${ }^{b} \dot{I}$ stanbul University, İstanbul 34452, Turkey
}

\begin{abstract}
APA Citation:
Basal, A., Toraman, M., \& Celen, M. K. (2021). ONCOLL: A quasi-experimental study on the effect of a web-based platform on teaching collocations. Eurasian Journal of Applied Linguistics, 7(1), 68-84.
\end{abstract}

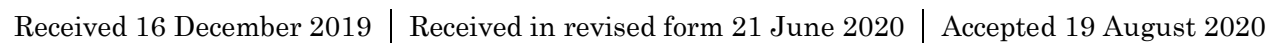

Doi: $10.32601 /$ ejal.911181

\begin{abstract}
Learning collocations poses difficulties for foreign language learners despite their importance for fluency in the target language. Collocation learning and teaching should therefore be an integral part of foreign language instruction. With a focus on the receptive knowledge of collocations, this 5-week-long pretest/posttest quasi-experimental study aims to investigate the effectiveness of the use of an ONline COLLocation learning platform (ONCOLL) designed specifically for the explicit teaching of English adjective-noun collocations over traditional activities. Sixty-two first-year students from an English Language Teaching Department at a university were the participants of the study. Each week, the participants were provided with 10 sample sentences including the target adjective-noun collocations which were followed by two sets of exercises. While the control group $(n=29)$ completed all the procedures with paper-and-pen materials and under the guidance of their teacher, the participants in the experimental group $(n=33)$ used ONCOLL on individual computers and without the teacher's involvement. For data collection, an achievement test including 50 items was used as the pre- and post-test to determine whether differences between the two groups were statistically significant. Based on the results, the experimental group participants scored significantly higher than the participants of the control group, indicating the effectiveness of ONCOLL in learning collocations in a foreign language. This discrepancy could be attributed to some of ONCOLL's features such as 1) providing room for individualized learning, 2) requiring the analysis of all example sentences by the learners, and 3) requiring the learners to take the tests in the system repeatedly until they get a full score without any feedback.
\end{abstract}

(C) 2021 EJAL \& the Authors. Published by Eurasian Journal of Applied Linguistics (EJAL). This is an open-access article distributed under the terms and conditions of the Creative Commons Attribution license (CC BY-NC-ND) (http://creativecommons.org/licenses/bync-nd/4.0/).

Keywords: Collocation; English language teaching; online system; vocabulary teaching

\section{Introduction}

Becoming fluent in a foreign language (FL) is a challenging task. There seemingly exists a high correlation between fluency and vocabulary knowledge of the language learners. Vocabulary learning and teaching should therefore be an integral part of foreign language instruction. There is common agreement among researchers that increasing vocabulary

\footnotetext{
* Corresponding author. Tel.: +090-212-383-4877

E-mail address: ahmetbasal@gmail.com

http://dx.doi.org/10.32601/ejal.911181
} 
knowledge is not an easy task (Laufer, 2017). Collocations occupy an important place in this regard.

Collocations (e.g., hot debate, violate a rule, widely known, make a mistake, running water) are language patterns that can be described as "the habitual association of a word in a language with other particular words in sentences" (Robins, 2000, p. 64). McCarthy (1990) has applied the metaphor "a marriage contract between words" (p.12) to show this strong bond and emphasized the importance of collocational knowledge in vocabulary learning. Collocational knowledge is accepted as an indicator of more natural production and fluency in the target language (Ellis et al., 2015; Laufer, 2011; Schmitt, 2012) and is important for fluency in the target language (Wu, Franken, \& Witten, 2010). Despite the importance of collocational knowledge, a huge gap exists between learners and native speakers in terms of their collocation repertoire, and foreign language learners are slow to close the gap (Boers \& Lindstromberg, 2012). It is plausible to argue that the number of collocations one knows is what distinguishes learners from native speakers (Wu et al., 2010). Research consistently shows that foreign language learners experience problems due to their limited collocational knowledge (e.g., Bahns \& Eldaw, 1993; Farghal \& Obiedat,1995) and most of them are quite slow in acquiring collocations for various reasons such as limited exposure, lack of awareness, and lack of appropriate ways of learning.

There has been a significant increase in collocation studies in recent years (Wray, 2012). Despite the utmost importance of collocations, Gatbonton and Segalowitz (2005) claimed that limited studies have put forward ways to increase collocational knowledge. Besides, Dóczi and Kormos (2016) pointed to the inadequacy of research that focused on the teaching and learning dimensions of formulaic language. In addition, Chan and Liou (2005) claim that collocations are mostly taught in classroom settings, which may be an ineffective way of teaching collocations since the presentation of collocation examples by teachers can be a daunting task. Due to possible differences between teaching single words and collocations, teaching them with the use of computers is a good and easy option, creating more exercise types (Nesselhauf \& Tschichold, 2002). The use of technology is common in language learning (Golonka, Bowles, Frank, Richardson, \& Freynik, 2014) including vocabulary teaching. In fact, technology has affected teaching and learning remarkably (Pavlik, 2015) and foreign language teaching experts increasingly realize the affordances of emerging technologies.

Certain studies have put technology into use for collocation teaching and learning (e.g., $\mathrm{Wu}$ et al., 2016). Basal (2019) found that using online tools together (namely concordance, online collocation dictionary, the web as a corpus, and Google Docs) in teaching collocations yielded significantly higher gains than a traditional approach. In a study conducted by Nurmukhamedov (2017), the use of an online dictionary (namely the Longman Dictionary of Contemporary English (LDOCE) and an online tool (namely www.wordandphrase.info (WPI)) give better results over the use of a hardcover dictionary (namely the Macmillan Collocation Dictionary (MCD)) in producing more accurate collocations in L2 writers' essays, and also L2 writers preferred to use the online tool for easy navigation. It has also been shown that using concordances is a more effective way of 
teaching collocations than a traditional approach (Daskalovska, 2015). Daskalovska suggested reasons in favor of the corpus-based activities over the traditional approach; the activities a) provide more information about the collocations, b) are more engaging since students behave as discoverers of collocations, and c) enable learners to conduct in-depth analysis on collocations. However, concordancers, a key element in DDL (data-drivenlearning), may not be adequate to help learners to see collocations, and some specific tools are needed to undertake this task (Chen, 2011). Using DDL in teaching collocations may require training on the part of the students and teachers since corpora are designed and developed mainly for researchers, linguists, and advanced users. The concordance lines may also include advanced vocabulary, complex grammar structures, and culturally sensitive information, causing confusion and inconvenience on the part of the learner.

In addition to the contributions of technology to the teaching and learning of L2 collocations, the role played by different instructional approaches (i.e., implicit and explicit) has been an area of interest in the literature. Among the variables investigated have been the types of collocations targeted and the manipulation of the frequency of exposure to the target collocations. In a study investigating the incidental learning of adjective-pseudoword collocations, Pellicer-Sánchez (2017) found that reading texts including collocations more frequent led to higher learning gains in recognition of target collocations than in recall. In another study that focused on congruency, collocate-node relationship, word length, and participants' vocabulary size, Peters (2016) required the use of an online platform for the participants to complete a series of exercises during the treatment. Following the completion of an exercise, the participants (with L1 Dutch) were provided with the correct answers to the items they had answered incorrectly if any. It was found that the collocate-node relationship constituted a significant predictor in learning collocations, with adjective-noun collocations eliciting the largest numbers of correct responses in all of the posttests (recall as well as recognition) used in the study. Webb, Newton and Chang looked into the incidental learning of collocations by using four graded readers in which the target collocations occurred with differing frequency (i.e., once, 5 times, 10 times, and 15 times). The participants read and listened to the graded readers at the same time. The largest learning gains, for both productive and receptive knowledge of collocations, were found for the participants who read the version where the target collocations occurred 15 times. It was further suggested that exposure to the target collocations 5 or more times might be necessary for incidental learning of the form of collocations. The studies detailed above, with a focus on incidental as well as explicit learning of collocations, adequately reflect the diversity and effect of research designs on the teaching and learning of L2 collocations. We believe that both explicit and implicit teaching of collocations have advantages and disadvantages. On the part of the explicit teaching, designing of the activities may have a direct effect on the teaching of collocations.

There has been a growing need for studies in foreign language teaching exploring the effects of technology on learning or proficiency since most of the studies so far have focused on the description of affordances of technology or measurements of students' affective reactions (Golonka et al., 2014). With a focus on the receptive knowledge of 
collocations, this study aims to investigate the effectiveness of the use of an online collocation learning platform (ONCOLL) designed specifically for the explicit teaching of adjective-noun collocations of 50 nouns from the Academic Word List (Coxhead, 2000). The following questions guided the current study:

1. Does explicit teaching of adjective-noun collocations lead to an improvement in participants' knowledge of these units?

2. Is there a difference in the effectiveness of learning adjective-noun collocations between a teacher-led classroom environment and the use of an online platform?

\section{Method}

\subsection{Research Design}

This five-week-long quasi-experimental study with a pretest-posttest design aimed to investigate the effectiveness of an online collocation learning platform (ONCOLL) on teaching adjective-noun collocations.

\subsection{Participants}

A convenience sample of 77 freshmen students from an ELT Department at a state university in Turkey was chosen for the study. Fifteen students were excluded from the study due to their attendance problems either in the lectures or achievement tests. The participants' language proficiency levels are upper-intermediate, based on their scores in the Foreign Language Exam (YDS), a component of the nationwide university entrance exams required for entry to the undergraduate program. The study was conducted in a compulsory course called Advanced Reading and Writing II in the spring semester of the academic year 2015-2016. Two different classes were taking the course in question. Traditional activities were used in one class (control group $n=29 ; m=4, f=25$ ) for teaching adjective-noun collocations; whereas ONCOLL was used in the other class (experimental group $\mathrm{n}=33 ; \mathrm{m}=16, \mathrm{f}=17$ ).

\subsection{Data Analysis}

The present study used the same activities and same achievement test as in Basal's (2019) study. The achievement test including 50 items (See Appendix A) was used as the pre- and post-test to determine whether differences between the two groups were statistically significant. According to Basal (2019), adjective-noun collocations in the achievement test were checked for their consistency based on the Oxford Collocation dictionary and internal validity was provided by taking the opinions of a panel of English language teaching experts. Moreover, two postgraduate native English speakers working as English instructors verified the adjective-noun combinations used in the test at a rate of $80 \%$ percent (interrater reliability). The remaining was verified after discussion and necessary changes were made based on the opinions of the same native speakers. To determine the reliability of the achievement test, Kudar-Richardson Formula 21 (KR21) 
was employed and the reliability coefficient was calculated as 0.92 , showing that the test is reliable and reliability was high.

For each correct answer in the achievement test, 1 point was given to the participants. Based on the comparison of pretest results of the control and experimental groups, no significant differences were found. The achievement test was also used as an immediate posttest after 5 weeks to check whether there were differences between the control group using traditional activities and the experimental group using ONCOLL for learning adjective-noun collocations. Due to time constraints, the post-test was conducted as an immediate posttest, only after one week of the intervention. Before performing the comparison test results within and between groups, the Shapiro-Wilk test was applied to check normality, and Levene's test was applied for homogeneity of variance. Based on the normality and homogeneity of variance tests, appropriate statistical tests were applied (see Results).

\subsection{Target Collocations}

This study used the same randomly selected 50 nouns from the Academic Word List (AWL) (Coxhead, 2000) and their adjective collocates as were used in Basal's study (2019) (See Appendix A). Adjective-noun collocations have so far been investigated in the literature with varying degrees of focus. Studies focusing, either solely or among others, on collocations as combinations of adjectives with nouns (e.g., Peters, 2016; Szudarski \& Carter, 2016) as well as nonwords (e.g., Pellicer-Sánchez, 2017) have provided much insight into the acquisition and assessment of these specific units. Through the use of a single type of collocation, but targeting the learning of a large number of these collocations, a more focused understanding of the instruction of L2 collocations is aimed for.

\subsection{About ONCOLL}

ONCOLL, a web-based platform with a user-friendly interface, was designed and developed to teach the target adjective-noun collocations to the participants in the experimental group. The participants in the experimental group could see a five-week training program presented in a vertical timeline on the platform. Each week consisted of 12 steps (see Figure 1). These steps were also the same in the hand-outs given to the control group. Each week, 10 nouns and their adjective collocations were presented in example sentences to the students in both groups (see Figure 2). The students were asked to read the example sentences and pay attention to the adjective-noun collocations presented in bold. The time spent on a task in class was same for both the control and experimental group. 


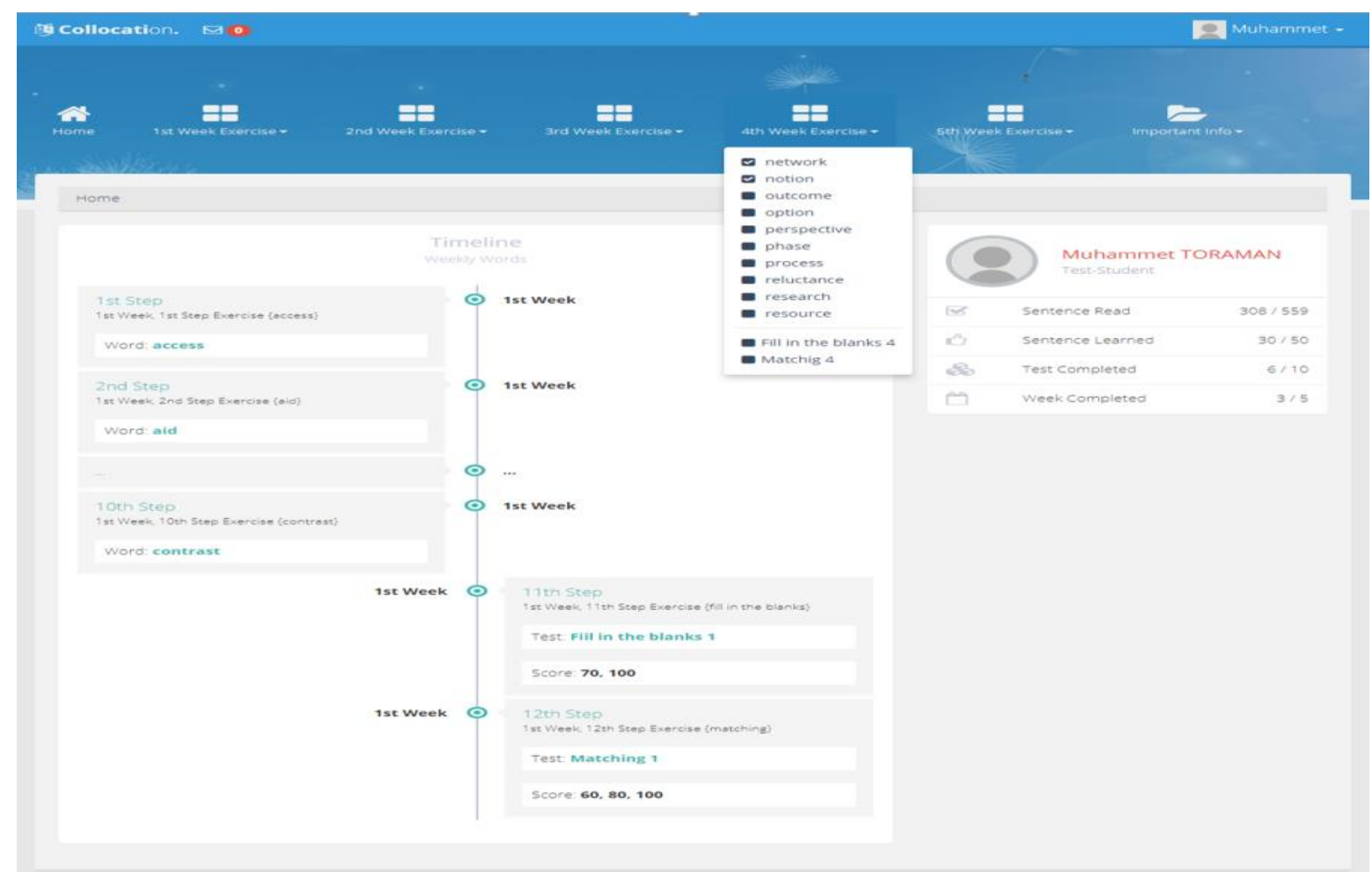

Figure 1. Sample screenshot of ONCOLL: Vertical weekly timeline

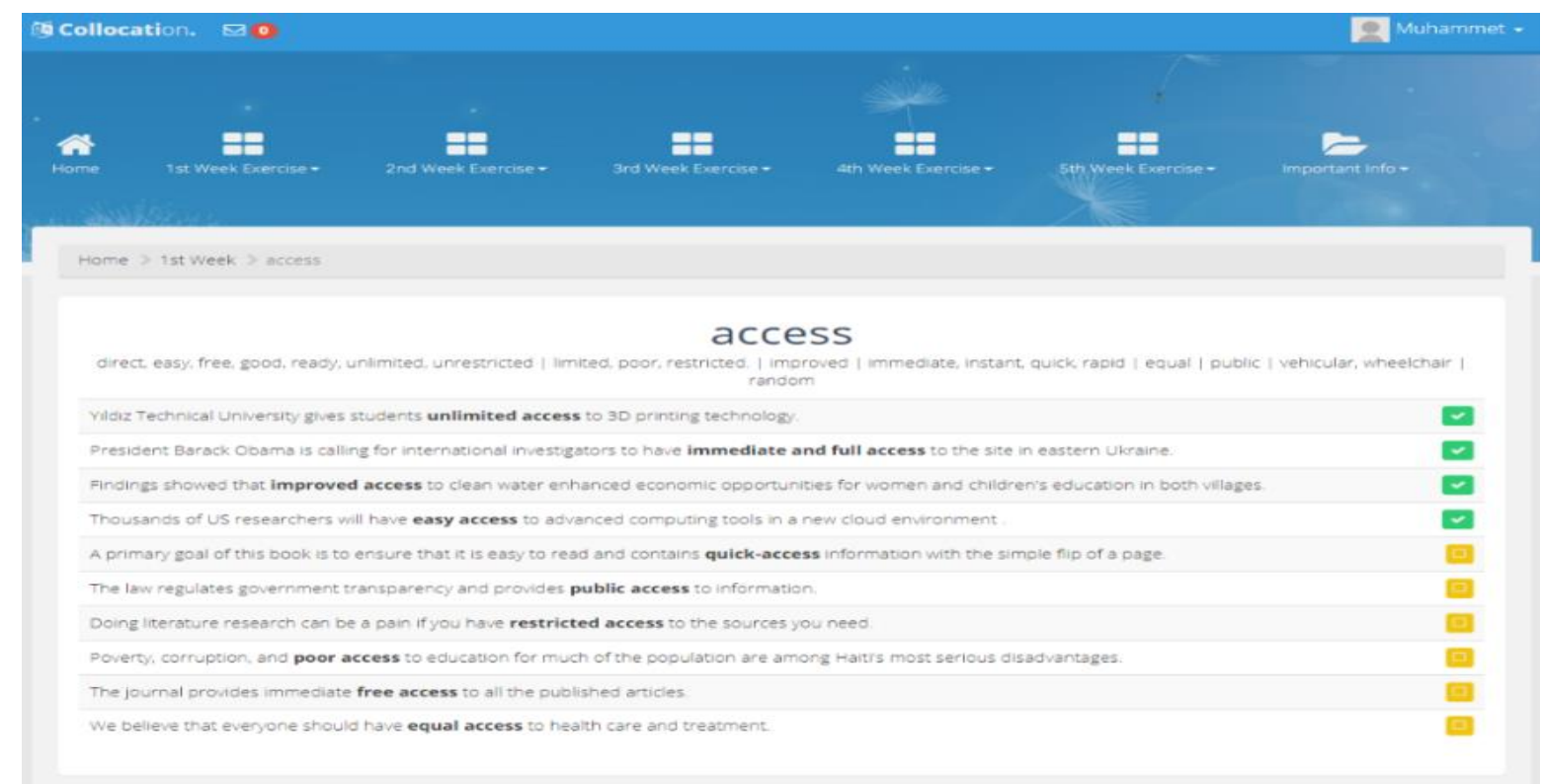

Figure 2. Sample Screenshot of ONCOLL: Adjective-noun collocations and example sentences (Green grids exemplify the sentences read by the participants and the yellow grids exemplify the sentences unread by the participants)

The participants were allowed to view the tests (there were two of them) only after checking the boxes given for each example sentence as a way of ensuring that they read all the example sentences. One of the tests was designed as 10 fill-in-the-blanks items (see Figure 3) while the other was in the format of two sets of matching exercises (see Figure 
4), each having five items. The sentences in the tests were different from those used in example sentences containing target collocations. The participants were required to take each test until they scored a compulsory score of 100 (i.e., full score). This means that the participants had to take the test repeatedly until they got a full score. After completing the tests with a full score of 100 , the participants were given access to the content for the following week. The participants were also able to track their progress based on performance information provided on the platform, namely (a) the number of sentences they had read, (b) the number of words they had learned, (c) the number of tests they had passed, and (d) the number of weeks they had completed. The ONCOLL platform did not show the participants which mistakes they had made in the exercises. Each participant in the experimental group had to do the exercises again until they found the correct answers by themselves. In other words, no hints were given to the participants by the ONCOLL.

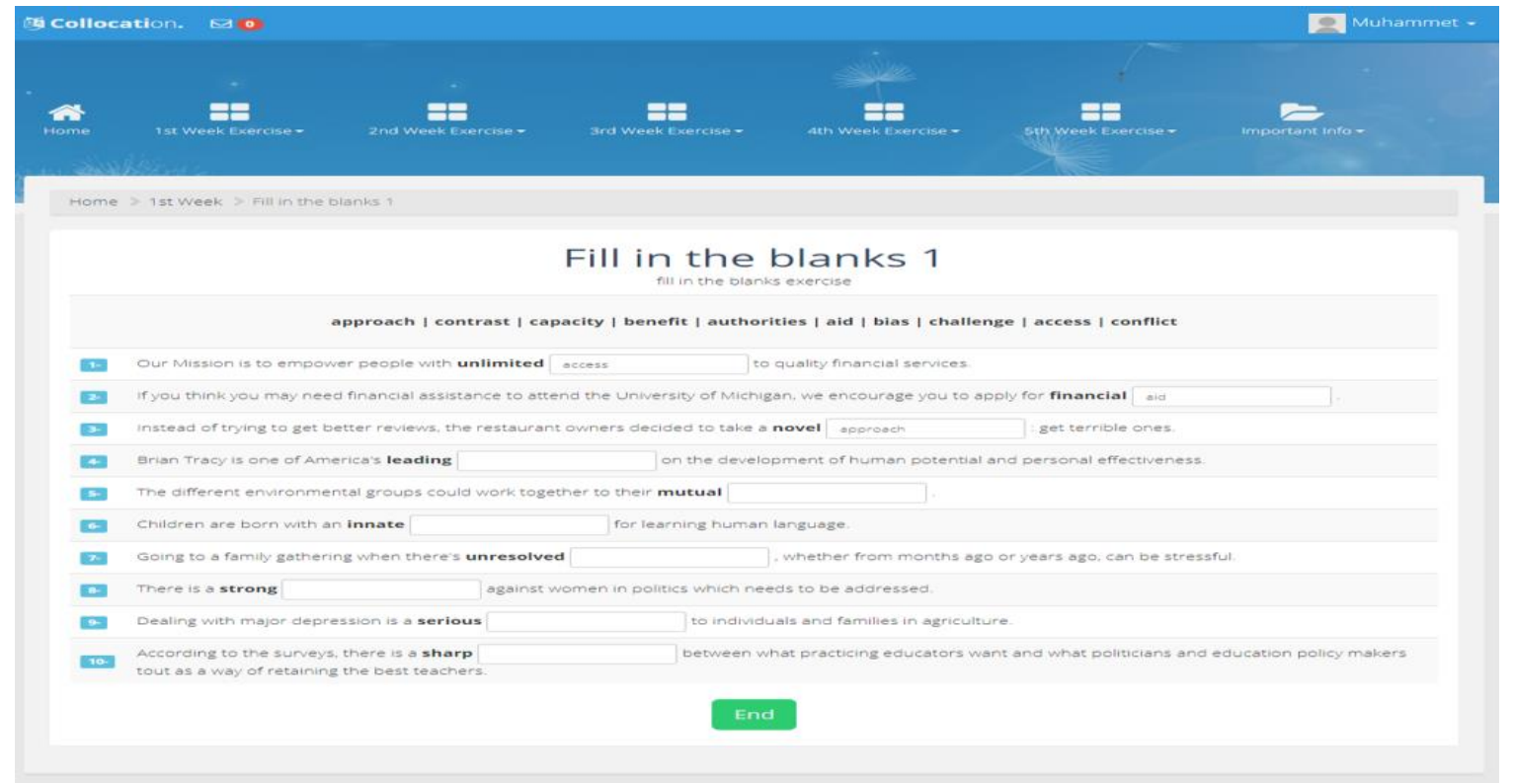

Figure 3. Sample screenshot of ONCOLL: Fill-in-the-blanks exercise 


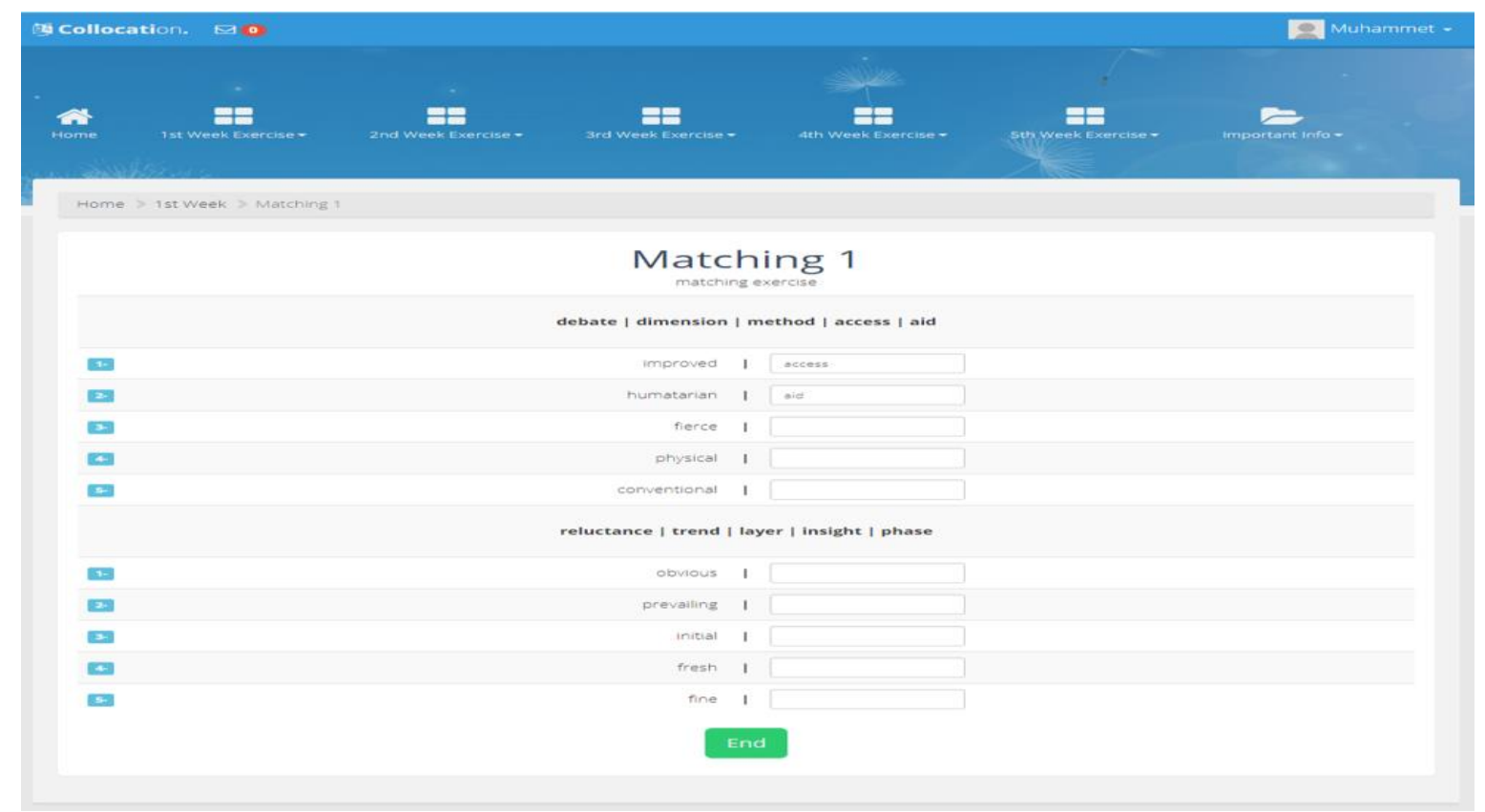

Figure 4. Sample screenshot of ONCOLL: Matching exercise

During five weeks, participants were given half an hour each week to work individually on computers assigned to them in the lab to complete the tasks. The example sentences for each week's targeted collocations, the fill-in-the-blanks and matching exercises (sentences used in these exercises are different from those used as example sentences) and the time for the sessions in each week (half an hour) were all same between the control and experimental groups. In the control group, the researcher as the teacher checked the answers and gave feedback to the students; in the experimental group, the ONCOLL platform checked all the answers and provided the correct answers for the incorrect ones, if any.

\subsection{Procedure}

The test consisted of gap-filling and matching (single words and two halves of a sentence) items, all of which measured the receptive knowledge of collocations. The gapfilling and single word matching items required the participants to use appropriate adjectives as well as nouns to form correct adjective-noun collocations. The test questions were different than those used in the example sentences and exercises given to the participants of both groups during the treatment.

During the first week of the study, participants in both groups were informed about the study. Traditional activities were used in the control group and the same activities were transformed to ONCOLL for the experimental group. For each of the subsequent weeks, the control group was given a handout with the target adjective-noun collocations assigned for that week. The handout included example sentences to showcase the adjective-noun collocations in context. The target collocations and example sentences were analyzed under the guidance of the teacher (one of the researchers) in the control group. The participants later completed two types of exercises focusing on the target adjective-noun 
collocations. The exercises included fill-in-the-blanks and matching items. The teacher gave feedback when a participant in the control group made a mistake since the strength of a teacher-led classroom environment (traditional approach) is that a teacher is there to give feedback to individual learners. This process took half an hour to complete each week. The participants also had the option to work on the targeted collocations in their free time with the handouts given. On the other hand, for teaching adjective-noun collocations, ONCOLL was used in the experimental group. Before its use, this web-based platform was introduced to the students. The participants of the experimental group did the same activities on ONCOLL. The target collocations and example sentences were analyzed individually by the participants in the experimental group. Then they completed the fill-inthe-blanks and matching exercises. ONCOLL gave feedback to the answers of the students. The experimental group was also taking the class from the same researcher but the researcher did not contribute to the learning process of the participants other than answering questions regarding the use of the ONCOLL platform. The process took half an hour to complete each week. However, ONCOLL was accessible to the participants of the experimental group throughout the five-week long study, allowing them to work on the targeted collocations through the platform in their free time (see Table 1).

Table 1. Steps of procedure in both groups

\begin{tabular}{|c|c|c|}
\hline \multicolumn{2}{|c|}{ Control G. } & Experimental G. \\
\hline Week 1 & Pre-test & Pre-test \\
\hline Week 2 & Teacher-lead (handouts) & Oncoll-lead \\
\hline Week 3 & Teacher-lead (handouts) & Oncoll-lead \\
\hline Week 4 & Teacher-lead (handouts) & Oncoll-lead \\
\hline Week 5 & Teacher-lead (handouts) & Oncoll-lead \\
\hline Week 6 & Teacher-lead (handouts) & Oncoll-lead \\
\hline Week 7 & Post-test & Post-test \\
\hline
\end{tabular}

* Handouts and Oncoll include the same set of 10 example sentences with targeted nouns and their adjective collocations and the same activities ("Fill-in the blanks" with 10 questions and "Matching" with 10 questions)

\section{Results}

In our study, there were 29 participants in the control group and 33 participants in the experimental group. Before performing the comparison tests, the Shapiro-Wilk test was applied to check the normality of control $(\mathrm{W}(29)=0.933, \mathrm{p}=0.0069)$ and experimental group $(\mathrm{W}(33)=0.971, \mathrm{p}=0.507)$ pre-tests. The results showed that normality was provided for the pre-tests. Levene's test also indicated that the groups had equal variances $(F=3,489$, $\mathrm{p}=.025$ ) and met the assumption of homogeneity of variance. No significant differences were expected between the pretest scores of the control and experimental groups before starting the intervention. To test this, Mann-Whitney U, a non-parametric test, was applied to compare the pre-test results of the control and the experimental group. Based on the results, no significant differences were found $(U=351.500, p=.073, z=-1,795)$ between the pre-test scores of experimental $(\mathrm{Mdn}=20.00)$ and control group $(\mathrm{Mdn}=23.00)$ (See Table 2).

Table 2. Descriptive statistics of achievement test for control and experimental groups 


\begin{tabular}{lllll}
\hline & & $\mathrm{N}$ & $\mathrm{M}$ & $\mathrm{SD}$ \\
\hline Control & pretest & 29 & 20.86 & 7.48 \\
& posttest & 29 & 33.41 & 6.97 \\
Experimental & pretest & 33 & 25.06 & 9.86 \\
& posttest & 33 & 42.09 & 5.54 \\
\hline
\end{tabular}

To answer the first research question of whether explicit teaching of adjective-noun collocations would result in learning, the pretest and posttest scores of the control group and the experimental group were compared within the groups. Before the comparison of the pre and post-test results of the control group, the Shapiro-Wilk test was applied to check normality. The results showed that normality $(\mathrm{W}(29)=0.970, \mathrm{p}=0.0059)$ was provided. Levene's test indicated equal variances $(\mathrm{F}=43,744, \mathrm{p}=.884)$, so dependent samples t-test, a parametric test, was applied for comparing two test conditions of the control group. When the pre-test $(\mathrm{M}=20.862, \mathrm{SE}=1,38)$ and post-test scores $(\mathrm{M}=33.414$, $\mathrm{SE}=1.29)$ of the control group were compared, significant gains $(\mathrm{t}(28)=-10.818, \mathrm{p}=.000$, effect size $=0.89$ ) were obtained. Before the comparison of the pre and post-test $(\mathrm{W}(33)=0.924, \mathrm{p}=0.024)$ results of the experimental group Shapiro-Wilk test was used for checking normality. The results showed that normality were provided for pre-test $(\mathrm{W}(33)=0.971, \mathrm{p}=0.507)$ but not for post-test $(\mathrm{W}(33)=0.924, \mathrm{p}=0.024)$. Levene's test also indicated unequal variances $(\mathrm{F}=74,799, \mathrm{p}=.001)$, so Wilcoxon, a nonparametric test, was applied for comparing two test conditions of the experimental group. When the pre ( $\mathrm{Mdn}=$ 23.00) and post-test $(\mathrm{Mdn}=43.00)$ results of the academic achievement test for the experimental group were analyzed, post-test results are significantly higher than those of the pre-test $(\mathrm{t}=0, \mathrm{p}=0.000, \mathrm{z}=-5.015$, effect size $=0.62)$. These results show that both the control group and the experimental group obtained statistically significant gains at the end of the study, showing that both methods were effective in improving the participants' knowledge of adjective-noun collocations.

To answer the second research question and to check whether the use of ONCOLL led to more effective learning of adjective-noun collocations, post-test results of both groups were compared. Before comparison, the Shapiro-Wilk test was applied to check the normality of control $(\mathrm{W}(29)=0.970, \mathrm{p}=0.559)$ and experimental group $(\mathrm{W}(33)=0.924$, $\mathrm{p}=0.024$ ) post-tests. The results showed that normality was provided for the control group, but not for the experimental group, so the Mann-Whitney U test was used to compare the post-test results of the control and the experimental group. Post-test scores of the experimental group $(\mathrm{Mdn}=43.00)$ differed significantly from those of the control group $(\mathrm{Mdn}=32.00, \mathrm{U}=163.000, \mathrm{p}=.000$, effect size $=-0.57)$. The significant difference found in favor of the experimental group in the posttest shows that the ONCOLL platform was more effective than the traditional approach used in the control group in terms of teaching adjective-noun collocations.

\section{Discussion}

Learning collocations presents a major challenge for foreign language learners (Laufer, 2011; Nesselhauf, 2003). It is clear that there is a need for empirical studies to explore 
what is pedagogically sound for increasing collocational knowledge since incidental learning of collocations includes numerous problems (Boers et al., 2014). If collocations are not provided a lot more frequently in materials than they occur in authentic input, the chances of learning a large portion of collocations incidentally tend to be limited (Webb et al., 2013). The current study set out to explore the effectiveness of ONCOLL, a web-based platform designed and developed by the researchers of the current study, over traditional activities. To be precise, the current study set out to shed light on the use of a web-based platform named ONCOLL as a tool for learning collocations compared to doing the same activities in a traditional approach. The findings of the current study indicated that both groups improved their knowledge of adjective-noun collocations, regardless of the learning condition (i.e., learning under the guidance of the teacher or through the ONCOLL platform). This could be interpreted as a positive outcome of an explicit focus on collocations as an instructional strategy.

When the posttest results of the groups were compared, the participants in the experimental group, who used the ONCOLL platform for collocation learning performed significantly better. Given that the same activities and same procedures were used for both the experimental and control group, the significant difference between the groups in the posttest in favor of the experimental group may have been caused by the differences in the learning environments provided for each group. In the control group, the first author was responsible for conducting the whole process, whereas in the experimental group the ONCOLL platform was used by the participants, without the intervention of the teacher. In traditional collocation teaching in the classroom, teachers are generally active in and responsible for the whole process (Chan \& Liou, 2005). However, when considering the need for more innovative ways to teach collocations, since teaching them is generally not similar to teaching other types of vocabulary (Nesselhauf \& Tschichold, 2002), integration of technology into the teaching of collocations can become a viable option.

There is a growing body of empirical studies that set out to explore the effectiveness of various interventions, some of which explore some sort of technology for increasing foreign language learners' collocational knowledge (e.g., Basal, 2019; Daskalovska, 2015; Nurmukhamedov, 2017; Wu et al., 2010). In a similar study to the current study, conducted by Mirzaei et al. (2016), a computer platform, LexisBOARD, a combination of a dictionary, corpus, visual presentations, tests, and feedback, was designed and used to teach lexical items (e.g., concordances, polywords, or formulaic sequences). The participants in the experimental group who used the platform got significantly higher scores in the achievement test compared to the control group, which is in line with the findings of the current study. In another study, Basal (2019) used a combination of online tools to teach adjective-noun collocations. He found that the experimental group doing activities with online tools got significantly higher scores in the posttest than the control group who used traditional activities. These studies support the idea that the affordances of technology may facilitate the process of learning collocations.

In a classroom setting, where students conduct all the activities under the guidance of the teacher, despite the huge efforts of teachers in planning the lecture, designing and developing the activities, and guiding the whole learning process, there is relatively less 
room for individualized learning when compared to web-based learning environments, where the system is responsible for the whole process. In ONCOLL, each of the participants in the experimental group learned collocations at their own pace. The system requires them to read all the example sentences (adjective-noun collocations in context). Moreover, the program did not show correct answers to the two exercises after each set of collocations (10 nouns and their collocations), compelling the participants to retake the tests until they got a compulsory score of 100. ONCOLL includes features such as answering questions at one's own pace and checking answers which are in fact in line with Keller's Personalized System of Instruction (Akera, 2017) and Skinner's Programmed Instruction (Singh, 2017). These features may have contributed to the significant posttest score gains on the part of the participants in the experimental group. This study shows that benefitting from technology is a more effective approach in teaching collocations.

One feature of ONCOLL might have also contributed to the larger number of gains observed in the experimental group: the full score requirement for the participants to finalize a test. The participants using ONCOLL were required to retake the entire exercise if they answered one or more items incorrectly. This implies that every error a participant made while doing the exercises meant another encounter with the target constituents. Although the frequency of exposure to target collocations does not guarantee better learning (Pellicer-Sánchez, 2017), there is some evidence (e.g., Webb et al., 2013) that it might have positive outcomes on the learning of collocations. According to Ellis (2002), frequency is a major predictor of vocabulary learning and language acquisition. Based on the findings of their study, Szudarski and Carter (2016) reported that an increased amount of repetition would not necessarily lead to improvement for every aspect of the knowledge of collocations. Indeed, their study demonstrated that form recognition of underlined collocations was achieved best when the participants were exposed to them 6 times, with a repetition of 12 times not eliciting more improvement. Therefore, although the online platform used in the present study provided forced exposure to the target collocations and example sentences, commensurate with learner performance, the positive effects of such a feature might not be absolute, but nevertheless, deserve attention. It is possible to suggest that exposure frequency may have been an important factor in the significant gains of the experimental group. The full score requirement of the ONCOLL platform may have led to more encounters with the target items. On the other hand, in the control group, the teacher (one of the researchers) was responsible for checking the answers to exercises and give feedback, which was an exhausting process. The use of technology in this process is as one can imagine a more appropriate approach to ease the burden of the teachers.

Pellicer-Sánchez (2017) states that the findings found for a certain type of collocation might not be directly applicable to other types of collocations due to "the multifarious nature of collocations" (p. 387). Therefore, the positive effects of the use of ONCOLL in this study should be interpreted with caution. In addition to the type of collocations, the type of tests used in the present study to measure the participants' performance needs to be taken into consideration while interpreting the results. Peters (2016) found that the likelihood of eliciting correct adjective-noun collocations was highest with the form recognition test in comparison to two different form recall tests used in her study, one of 
which required congruency for the collocate-node relationship to show its effect. Because the posttest used in the present study only measured participants' recognition of adjectivenoun collocations, it portrays only one aspect of the participants' knowledge of collocations. Although we agree with Webb et al. (2013), who state that "measuring multiple aspects of collocational knowledge should provide a more accurate assessment of learning than measuring a single aspect, and measuring each aspect at ... [receptive and productive levels] should help to show the extent to which each of those aspects are learned" (p. 102), we opted for a single measure to test learners' gain. With a total of 50 adjective-noun collocations set as the target for the participants in the present study, form recognition of these combinations as an initial instructional target might also be interpreted as an achievable aim on the part of the participants.

\section{Conclusions}

For foreign language learners, knowledge of collocations is important for being fluent in the target language. However, it represents considerable difficulties and major challenges (Laufer, 2011; Nesselhauf, 2003). In this process, providing help and support to language learners is important. However, in foreign language classes, collocation teaching is generally a neglected, or at least a limited aspect (Basal, 2019). On the other hand, learning collocations incidentally is also not without problems (Boers et al., 2014). It is therefore a must to help language learners on this thorny road. Thus, integrating technology in this process can be a viable option.

Along with the technological advances, we have been increasingly witnessing the use of various technologies to support learning and teaching environments, and foreign language teaching is no exception. In this study, we aimed to find an ideal method that may help language learners to overcome the difficulties encountered during collocation learning. To this end, we designed and developed a web-based platform (ONCOLL) to be used in the process of teaching collocations to English language learners. We focused on investigating the effectiveness of ONCOLL in teaching adjective-noun collocations over traditional approaches. Our findings revealed significant differences in favor of the experimental group in the posttest, indicating the effectiveness of ONCOLL compared to the traditional approach used in the control group in the teaching of adjective-noun collocations. The advantages of using ONCOLL over traditional teacher-conducted classroom activities or other technology-based platforms can be summarized as follows: ONCOLL requires the analysis of all sentences provided (adjective-noun collocation in context) by the learners. The system also provides opportunities for individualized learning where learners see the adjective-noun collocations in example sentences, check the answers of the exercises, and continue to other collocation combinations. In other words, ONCOLL can help learners to study and master the content at their own pace. Also, ONCOLL requires the learners to retake each test repeatedly until they scored a compulsory score of 100 (i.e., full score) and find all the correct answers by themselves without feedback from the system. This may have also contributed to the exposure frequency of the collocations. Besides, ONCOLL requires the students to take ownership of their learning and creates an independent learning environment of collocations. It can be stated that when technology is used 
appropriately in collocation teaching, it facilitates the learning of them, helping foreign language learners overcome the difficulties encountered in the process of learning collocations. It is concluded that technology integration into collocation teaching can create a favorable learning environment and give fruitful results.

\subsection{Limitations and further research}

This study has some limitations. Firstly, we focused only on teaching adjective-noun collocations of English with a web-based platform. However, including different types of target collocations might have affected the results differently. Because adjective-noun collocations are subject to fewer changes in morphology than (phrasal) verb-noun collocations (Peters, 2016), the effectiveness of similar learning platforms should be investigated in teaching other types of collocations. Secondly, the experimental group may have obtained significant score gains due to the novelty effect since the platform used in the study was new to the participants of the experimental group. Thirdly, this study did not use delayed post-tests to measure whether the superior performance achieved by the experimental group was durable. Therefore, the long-term effects of the intervention need to be investigated in further studies to elicit a more comprehensive understanding of the relative effectiveness of web-based tools in the teaching and learning of collocations. Another limitation of the study is not measuring or controlling for the number of encounters with the target collocations. Future studies may also focus on the frequency of exposure to the collocations. Finally, one of the distinguishing features of ONCOLL was the obligatory repetition of the tests, which came into use when there was at least one item answered incorrectly. However, the number of errors made by each participant in each test as well as the number of trials it took for them to complete each test session were not investigated in the present study. Therefore, further research may look into individualized learning gains of individual participants who use online platforms, by focusing also on errors and how these errors are corrected (e.g., after how many trials). Further, how consistently the participants answer a particular item correctly or incorrectly remains another area for investigation. ONCOLL may have considerable potential in supporting collocation learning. The future development/enhancement of the platform could include using authentic texts in various contexts and language activities going beyond drill-andpractice exercises, particularly those that help learners notice the formulaic nature of the language. After this kind of development, its effectiveness can be tested again.

\section{Acknowledgments}

We would like to thank anonymous reviewers of this study for their constructive feedback.

\section{The Research and Publication Ethics Statement}

The authors ensure that no ethical considerations were violated in this study. The participants were informed about the study and the identities of the participants were kept completely confidential. On request, the dataset of the study can be made available via email to the corresponding author. 


\section{The Conflict of Interest Statement}

In line with the statement of the Committee on Publication Ethics (COPE), we hereby declare that we had no conflicting interests regarding any parties of this study. This research completed in September 2017 has been supported by Yildiz Technical University Scientific Research Projects Coordination Department Project Number: 2015-09-02KAP02 without any occurrence of conflicting interest in the manner of the author(s). The preliminary results of this paper were presented in the proceedings of the Ejer Congress 2016 in Muğla, Turkey.

\section{References}

Akera, A. (2017). Bringing radical behaviorism to revolutionary Brazil and back: Fred Keller's Personalized System of Instruction and Cold War engineering education. Journal of the History of the Behavioral Sciences, 53(4), 364-382. http://doi.org/gcvzcd

Bahns, J., \& Eldaw, M. (1993). Should we teach EFL students collocations? System, 21, 101114. http://doi.org/bnbd2f

Basal, A. (2019). Learning collocations: Effects of online tools on teaching English adjectivenoun collocations. British Journal of Educational Technology, 50(1), 342-356. http://doi.org/dnjs

Boers, F., \& Lindstromberg, S. (2012). Experimental and intervention studies on formulaic sequences in a second language. Annual Review of Applied Linguistics, 32, 83-110. http://doi.org/ggr4fg

Boers, F., Lindstromberg, S., \& Eyckmans, J. (2014). Some explanations for the slow acquisition of L2 collocations. VIAL-Vigo International Journal of Applied Linguistics, 11, 41-62.

Chan, T. P., \& Liou, H. C. (2005). Effects of web-based concordancing instruction on EFL students' learning of verb-noun collocations. Computer Assisted Language Learning, 18(3), 231-251. http://doi.org/ds6m7t

Chen, H. J. H. (2011). Developing and evaluating a web-based collocation retrieval tool for EFL students and teachers. Computer Assisted Language Learning, 24(1), 59-76.

Coxhead, A. (2000). A new academic word list. TESOL Quarterly, 34(2), 213-238. http://doi.org/bfvprv

Daskalovska, N. (2015). Corpus-based versus traditional learning of collocations. Computer Assisted Language Learning, 28, 130-144. http://doi.org/b4th

Dóczi, B., \& Kormos, J. (2016). Longitudinal developments in vocabulary knowledge and lexical organization. Oxford: Oxford University Press. http://doi.org/d27g

Ellis, N. C. (2002). Frequency effects in language processing: A review with implications for theories of implicit and explicit language acquisition. Studies in Second Language Acquisition, 24(2) 143-188.

Ellis, N. C., Simpson-Vlach, R., Römer, U., Brook O’Donnell, M., \& Wulff, S. (2015). Learner corpora and formulaic language in second language acquisition. In S. Granger, G. Gilquin, \& F. Meunier (Eds.), The Cambridge handbook of learner corpus research (pp. 357-378). Cambridge: Cambridge University Press. http://doi.org/d27h

Farghal, M., \& Obiedat, H. (1995). Collocations: A neglected variable in EFL. IRAL, 33(4), 315333. http://doi.org/crptrv 
Gatbonton, E., \& Segalowitz, N. (2005). Rethinking communicative language teaching: A focus on access to fluency. Canadian Modern Language Review, 61(3), 325-353. http://doi.org/d9hpxs

Golonka, E. M., Bowles, A. R., Frank, V. M., Richardson, D. L., \& Freynik, S. (2014). Technologies for foreign language learning: a review of technology types and their effectiveness. Computer Assisted Language Learning, 27(1), 70-105. http://doi.org/ggfncd

Laufer, B. (2011). The contribution of dictionary use to the production and retention of collocations in a second language. International Journal of Lexicography, 24(1), 29-49. http://doi.org/b7r7jv

Laufer, B. (2017). From word parts to full texts: Searching for effective methods of vocabulary learning. Language Teaching Research, 21(1), 5-11. http://doi.org/d27j

McCarthy, M. (1990). Vocabulary. Oxford: Oxford University Press.

Mirzaei, A., Domakani, M. R., \& Rahimi, S. (2016). Computerized lexis-based instruction in EFL classrooms: Using multi-purpose LexisBOARD to teach L2 vocabulary. ReCALL, 28(1), 22-43. http://doi.org/gfdck5

Nesselhauf, N. (2003). The use of collocations by advanced learners of English and some implications for teaching. Applied Linguistics, 24(2), 223-242. http://doi.org/fh99d4

Nesselhauf, N., \& Tschichold, C. (2002). Collocations in CALL: An investigation of vocabularybuilding software for EFL. Computer Assisted Language Learning, 15(3), 251-279. http://doi.org/ckww7z

Nurmukhamedov, U. (2017). The contribution of collocation tools to collocation correction in second language writing. International Journal of Lexicography, 30(4), 454-482. http://doi.org/d27k

Pavlik, J. V. (2015). Fueling a third paradigm of education: The pedagogical implications of digital, social and mobile media. Contemporary Educational Technology, 6(2), 113-125.

Pellicer-Sánchez, A. (2017). Learning L2 collocations incidentally from reading. Language Teaching Research, 21(3), 381-402. http://doi.org/d27m

Peters, E. (2016). The learning burden of collocations: The role of interlexical and intralexical factors. Language Teaching Research, 20(1), 113-138. http://doi.org/d27n

Robins, R. H. (2000). General linguistics (4th ed.). Beijing: Foreign Language Teaching and Research Press.

Schmitt, N. (2012). Formulaic language and collocation. In C. Chapelle (Ed.), The encyclopedia of applied linguistics (pp. 1-10). New York: Blackwell. http://doi.org/d27p

Singh, V. (2017). Effectiveness of programme learning material for teaching physics in class X. Voice of Research, 5(4), 13-14.

Szudarski, P., \& Carter, R. (2016). The role of input flood and input enhancement in EFL learners' acquisition of collocations. International Journal of Applied Linguistics, 26(2), 245-265. http://doi.org/d27a

Webb, S., Newton, J., \& Chang, A. (2013). Incidental learning of collocation. Language Learning, 63(1), 91-120. http://doi.org/f4n5qt

Wray, A. (2012). What do we (think we) know about formulaic language? An evaluation of the current state of play. Annual Review of Applied Linguistics, 32, 231-254. http://doi.org/d27r

Wu, S., Franken, M., \& Witten, I. H. (2010). Supporting collocation learning with a digital library. Computer Assisted Language Learning, 23(1), 87-110. http://doi.org/fcr735

Wu, S., Li, L., Witten, I. H., \& Yu, A. (2016). Constructing a collocation learning system from the Wikipedia Corpus. International Journal of Computer-Assisted Language Learning and Teaching (IJCALLT), 6(3), 18-35. http://doi.org/d27s 


\section{Appendix A. Target nouns for adjective collocations and samples of test questions (Basal, 2019).}

Target Nouns for Adjective Collocations: access, aid, approach, authority, benefit, bias capacity, challenge, conflict, contrast, data, debate, decline, dimension, emphasis, estimate, feature, foundation, framework, goal, grade, guideline, ignorance, impact, input, insight, issue, label, layer, method, network, notion, outcome, option, perspective, phase, process, reluctance, research, resource, revolution, role, schedule, survey. target, task, tradition, trend, version, vision.

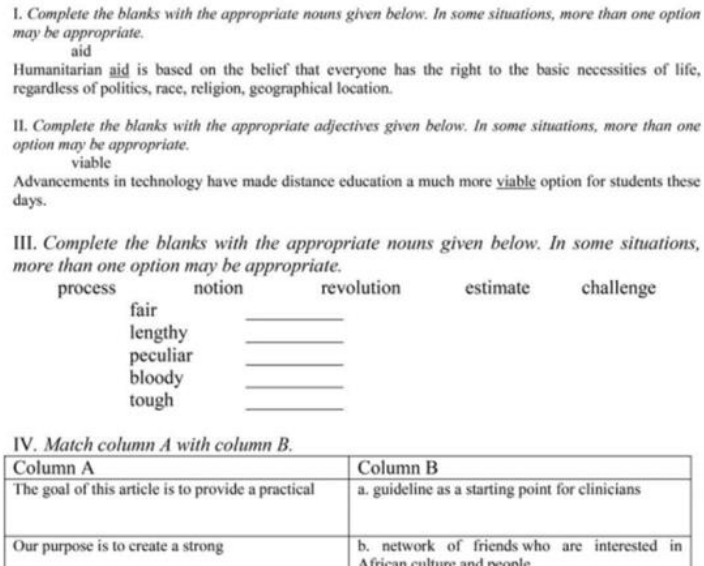

V. Complete the blanks with the appropriate adjectives given below. In some situations, more than one option may be appropriate.
burning poor scarce comprehensive stark

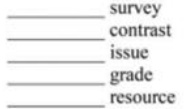

\section{Copyrights}

Copyright for this article is retained by the author(s), with first publication rights granted to the Journal. This is an open-access article distributed under the terms and conditions of the Creative Commons Attribution license (CC BY-NC-ND) (http://creativecommons.org/licenses/by-nc-nd/4.0/). 